\title{
Extending The Technology Acceptance Model: Policy Acceptance Model (PAM)
}

Tamra P. Pierce, The George Washington University (GWU) \& CACI International Inc., USA

Christopher Willy, The George Washington University (GWU), USA

Robert Roncace, The George Washington University (GWU), USA

John Bischoff, The George Washington University (GWU), USA

\begin{abstract}
Many have studied the process of acceptance and adoption of new ideas and technologies as they are introduced into society. While several models have been used to assess various influencing factors, the Technology Acceptance Model (TAM) is one that is most widely accepted. This model examines people's acceptance of new technologies based on variables that directly correlate to how the end user views the product. This paper introduces the Policy Acceptance Model (PAM), an expansion of TAM, which is designed for the analysis and evaluation of acceptance of new policy implementation. PAM includes the traditional constructs of TAM and adds the variables of age and ethnicity. The model is experimentally assessed using a survey of people's attitudes toward the upcoming health care reform from 72 survey respondents. The aim is that the theory behind this model can be used as a framework that will be applicable to studies looking at the introduction of any new or modified policies.
\end{abstract}

Keywords: Age; Ethnicity; Health care; Health care Reform; Technology Acceptance Model (TAM); Theory Of Planned Behavior (TPB); Policy Acceptance Model (PAM)

\section{INTRODUCTION}

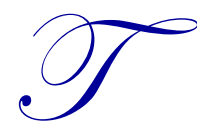

echnology acceptance research is a mature field with many models and theories developed and tested (Aggelidis, 2009). However, despite the large volume of work in this area, research has not been conducted in policy acceptance, indicating a significant gap in knowledge. A wide range of technologies, including e-mail programs, internet banking, electronic commerce applications, word processors, electronic meeting systems, medical equipment and tools for computer-aided software engineering, have been studied (Bricon-Souf, 2007). Existing acceptance models concentrate on a variety of variables and provide a detailed analysis structure for each aspect and attempt to explain this acceptance or rejection of new technologies. TAM has been used in numerous cases in its original form and extended to include additional variables to cover non-technology ideas.

In TAM, technology acceptance and use is determined by behavioral intent (BI), which is affected by attitude towards use (ATT), and the direct and indirect effects of perceived ease of use (PEOU) and perceived usefulness (PU) (Davis, 1985; 1989). PU and PEOU are influenced by external variables - age, gender, specific characteristics of user (Teo, 2010; Vale, 2004; Venkatesh, 2002). It has been experimentally proven that BI is the best predictor of actual use (Davis, 1989; Scott, 2007; Venkatesh, 2003). TAM is an analytical model that looks at functionality to understand why users have particular beliefs and how they influence behavior.

TAM has been widely used to conduct research in the field of information systems and is beginning to break ground in other areas of study. In these extensions, additional variables are added to the model to create new models that expand on the original TAM. These studies analyze a variety of fields and display how TAM can be used as a basis to look at the acceptance of ideas outside of information systems. 
The primary aim of this research is to:

1. provide an example of how the TAM structure may be extended to include age and ethnicity variables

2. test the applicability and effectiveness of TAM in the policy sector using a random subset of the population and an example policy issue

In order to achieve these goals, an extended TAM is developed and tested using a structural equation modeling (SEM) approach.

\section{LITERATURE REVIEW}

\section{Acceptance Models}

Numerous studies about technology acceptance have been conducted in different fields. Some of the technologies and applications being tested include e-mail programs, internet banking, electronic commerce applications, word processors, electronic meeting systems and tools for computer-aided software engineering (Rocker, 2010). Several models have come out of this research which attempt to explain this acceptance or rejection (Table 1).

Table 1: Overview Of Existing Acceptance Models

\begin{tabular}{|c|c|c|c|}
\hline Acceptance Models & Influencing Factors & Summary & $\begin{array}{c}\text { Suitability For Policy } \\
\text { Acceptance }\end{array}$ \\
\hline $\begin{array}{l}\text { Theory Of Reasoned Action } \\
\text { (TRA), Fishbein And Ajzen, } \\
1975\end{array}$ & $\begin{array}{l}\text { Belief and Evaluations, } \\
\text { Normative Beliefs, Attitude, } \\
\text { Subjective Norm }\end{array}$ & $\begin{array}{l}\text { Behavior intention based } \\
\text { purely on a person's attitude }\end{array}$ & $\begin{array}{l}\text { Intended in prediction of } \\
\text { activities involving a choice } \\
\text { among alternatives, not in a } \\
\text { mandatory context }\end{array}$ \\
\hline $\begin{array}{l}\text { Theory Of Planned Behavior } \\
\text { (TPB), Ajzen, } 1991\end{array}$ & $\begin{array}{l}\text { Behavioral Attitude, } \\
\text { Subjective Norms, Perceived } \\
\text { Behavioral Control, } \\
\text { Behavioral Intention }\end{array}$ & $\begin{array}{l}\text { Measures an individual's } \\
\text { physical action }\end{array}$ & $\begin{array}{l}\text { Based on cognitive } \\
\text { processing and behavior } \\
\text { change and not cognitive } \\
\text { acceptance }\end{array}$ \\
\hline $\begin{array}{l}\text { Technology Acceptance } \\
\text { Model (Tam), Davis } 1989\end{array}$ & $\begin{array}{l}\text { (perceived) Usefulness, } \\
\text { (perceived) Ease of Use, } \\
\text { Attitude Towards Use }\end{array}$ & $\begin{array}{l}\text { Disjunction between Benefit } \\
\text { and Effort as basic criteria } \\
\text { for Acceptance Decision }\end{array}$ & $\begin{array}{l}\text { No consideration for non- } \\
\text { technology applications }\end{array}$ \\
\hline $\begin{array}{l}\text { Unified Theory Of } \\
\text { Acceptance And Use Of } \\
\text { Technology (UTAUT), } \\
\text { Venkatesh, } 2003\end{array}$ & $\begin{array}{l}\text { Performance Expectancy, } \\
\text { Effort Expectancy, Social } \\
\text { Influence, Facilitating } \\
\text { Conditions }\end{array}$ & $\begin{array}{l}\text { Gender, Age, Experience, } \\
\text { and voluntariness of use } \\
\text { moderate impact of four key } \\
\text { constraints; Adoption and } \\
\text { diffusion of IS/IT }\end{array}$ & $\begin{array}{l}\text { Model contains too many } \\
\text { variables and becomes } \\
\text { difficult to analyze }\end{array}$ \\
\hline
\end{tabular}

\section{Technology Acceptance Model}

The original TAM (Figure 1) was built on the TRA of Fishbein and Ajzen (1975). In 1985, Fred Davis proposed the TAM in his doctoral thesis at MIT Sloan School of Management as a way to explain computer-usage behavior. TAM posits that PU and PEOU are of primary relevance for computer acceptance behaviors. In this model, Davis omitted subjective norm (SN) and BI which were in TRA. SN was removed because in a user acceptance test, subjects will typically be seeing the target systems for the first time and not have received cues from referents upon which to draw normative inferences (Davis, 1985). BI was removed because intention reflects a decision that the person has made and the time required to form an intention was not expected to elapse prior to measurement (Davis, 1985). Davis concluded that future research on the role of subjective normative influences relative to the existing technology acceptance models may yield a more complete understanding of the dynamics of the user acceptance process (Davis, 1985). 
Figure 1. Technology Acceptance Model

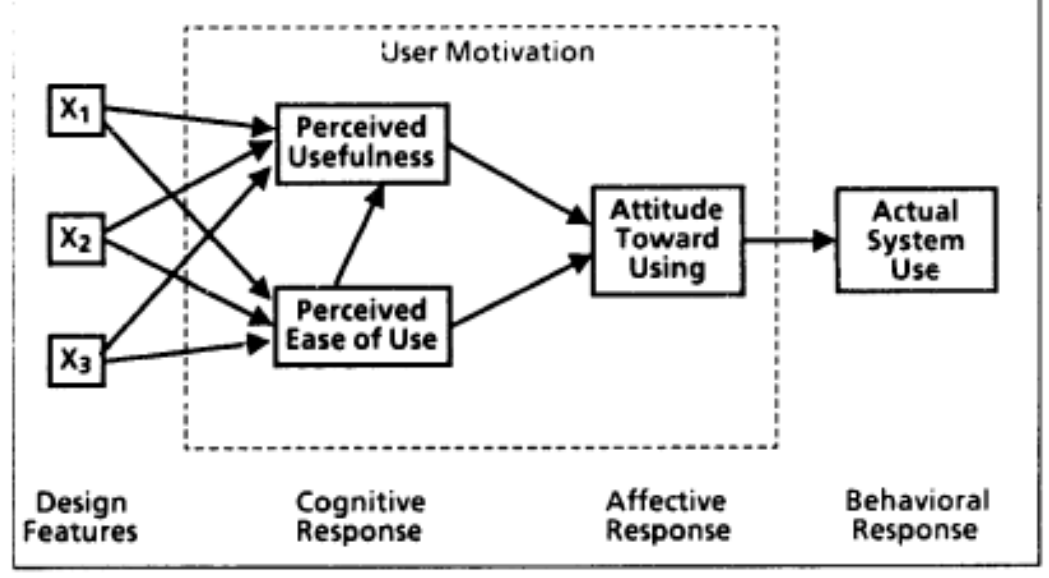

Figure 1: Technology Acceptance Model (Davis, 1985)

In 1989 in Davis' paper User Acceptance of Computer Technology, it was found that BI is a major determinant of usage behavior in both TRA and TAM. TAM was then modified and this construct was added (Figure 2) (Davis, 1989). Similar to TRA, TAM postulated that computer usage is determined by BI but differs in that BI is viewed as being jointly determined by the person's ATT and PU (Davis, 1989). It was found that a key purpose of TAM is to provide a basis for discovering the impact of external variables on internal beliefs, attitudes, and intentions (Yu, 2003). Throughout the years, TAM has received research support and has been extended to cover many different areas as seen in the TAM Extension section below.

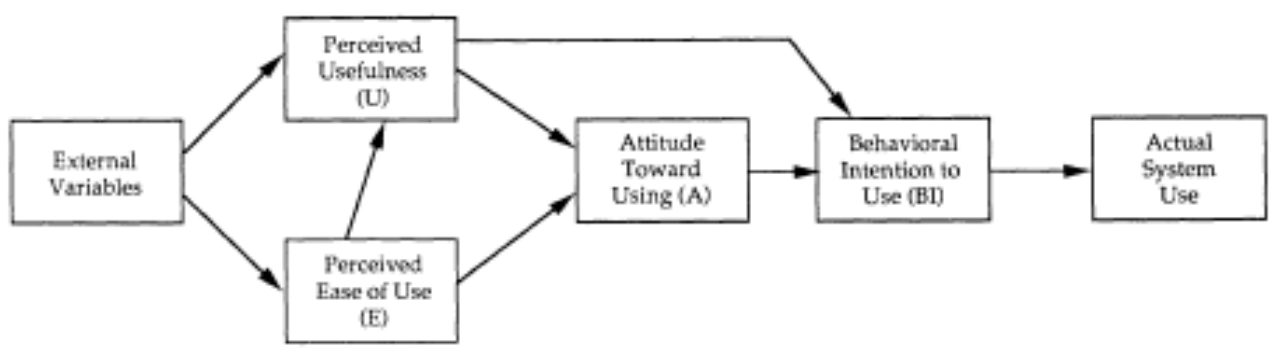

Figure 2: Technology Acceptance Model (Davis, 1989)

TAM is a widely accepted and cited model predicting system use and there have been many researchers to investigate TAM's overall explanatory power and measurement validity in various empirical environments characterized by group, technology and context (Hu, 1999). For example, there have been several studies of TAM that have tested the theory with students in the user group. Davis et al. investigated the validity of TAM and TRA in M.B.A. students' acceptance of a word processor application (Davis, 1989). Mathieson compared the utility of TAM and TPB in predicting the intention of undergrad students to use a PC-based spreadsheet application (Mathieson, 1991). In another study, Taylor and Todd examined the validity of TAM, together with TPB, explaining and predicting the use of a computer resource center by business school students (Taylor, 1995). Szajna evaluated TAM in an investigation of acceptance of an e-mail system by graduate students at a business college (Szajna, 1996). In 2013, Park used TAM to study the acceptance of tablet PCs with a web-based survey of undergrad students (Park, 2013).

The model has also been examined by non-student subjects. For example, Davis tested TAM using acceptance of an email system and word editor by employees at a large commercial organization (Davis, 1989). Holden analyzes TAM in health care and analyzes data sets in over 20 studies of clinicians using health IT for 
patient care (Holden, 2010). Lim used TAM to study consumers in shopping malls within Klang Valley, Malaysia and their acceptance of online shopping and how they form their attitudes and online shopping intentions (Lim, 2012). Pavlou also studied consumer acceptance of e-commerce and integrated trust and risk with TAM (Pavlou, 2003).

\section{TAM Extensions}

Historically, TAM has primarily been used to study technology acceptance; but through extensions, by adding additional variables, it has begun to be used to cover other areas. In the Compass Acceptance Model, TAM was extended to include perceived mobility and perceived costs to analyze and evaluate user acceptance of mobile services (Amberg, 2004). This model was used to verify user perception concerning user acceptance and better understand the types of users and the implication of service design. The application of CAM can be used to determine both the product development cycle and the product life cycle (Amberg, 2004).

In Modeling the acceptance of clinical information systems among hospital medical staff, the authors extend TAM to explain the intention to use medical information systems. They sample 604 medical staff and, using specialty as a moderator, test staff's information and communication technology (ICT) knowledge and ICT feature demands as external variables (Melas, 2011). The results show that TAM predicts a substantial portion of the intention to use clinical information systems.

In Technology Acceptance Model With Emotional Attachment (TAME), the authors' aim is to use this model to determine consumers' adoption of e-readers and look at whether attachment to paper books is a barrier to its adoption." The study suggests that consumers who are attached to products are more likely to be committed to them and willing to make sacrifices for them. This dedication may lead them to sacrifice the convenience of an ereader and continue the use of paper books. Another emotional attachment to paper books deals with the physicality. "They give rise to sensory pleasures and also to the cultural capital that comes with collecting and displaying books" (Read, 2011). In this study, the model focuses on consumer interests rather than TAM's original focus on the workplace. In the application of TAME, the researchers concluded that consumers' emotional attachment to paper books was weakly and negatively associated with their attitude toward e-reader technology. The model can further be used to understand consumers' emotional attachment to existing products and aid in the development of marketing new technologies (Read, 2011).

The Automation Acceptance Model (AAM) is an extension of TAM with the addition of task-technology compatibility and past experience. These variables were added to assess the role of human-automation interaction in automation adaption (Ghazizadeh, 2012). AAM was developed to integrate cognitive engineering and information systems perspectives into automation acceptance and reliance. The value of this framework is mainly for consumer products. The AAM shows acceptance as a dynamic bi-directional process rather than a single-directional process. Previous interactions with the system influence the user's perception of the system with then influence future interactions. With the addition of external variables, along with task-technology compatibility, trust in automation, perceived usefulness, ease of use, and influence of prior system use, the researchers in this article suggest that AAM is a more comprehensive framework for assessing automation acceptance (Ghazizadeh, 2012).

Srite and Karahanna studied how espoused national culture values at the individual level influence the acceptance of information technologies (Srite, 2006). "The study extended TAM by adding four espoused national culture variables - Masculinity/Femininity, Individualism/Collectivism, Power Distance, and Uncertainty Avoidance effects on the relationships between the TAM constructs" (Srite, 2006). The researchers make a contribution to cross-cultural research by treating culture not as a concept, but rather by dividing it into these four variables; then culture can be treated as individual separate constructs in theoretical models. This method used to model espoused culture and integrate it with other constructs generalizes across any number of individual level phenomena besides technology acceptance and provides a useful lens for examining cultural effects at the individual level of analysis (Srite, 2006). 


\section{Policy Implementation}

With the rising costs of health care, companies have experienced annual increases in health care spending of up to $8 \%$ in recent years, while the prices of their own products and services have increased by no more than 1$2 \%$ a year (Kocher, 2012). National health spending reached nearly $\$ 2.6$ trillion in 2010 and is projected to reach $\$ 4.5$ trillion in 2020. The health care system in the US is enormous and growing quickly, with the US spending more on health care than any other country in the world on a per capita basis (Harler, 2012). In 2010, the percentage of Americans without health insurance was $16.3 \%$, or 49.9 million uninsured people (Meltzer, 2011). While the economy is the first priority for most Americans, health care comes second (mentioned by 21 percent), followed closely by foreign policy (18 percent) (Kocher, 2012).

There are many challenges in the current US health care system, including rising cost, variable access and quality, fragmented delivery, geographic workforce misalignments, and barriers to translation and innovation (Meltzer, 2011). Three federal initiatives - the Health Information Technology for Economic and Clinical Health (HITECH) Act, the Health Data Initiative, and the Affordable Care Act - are designed to help make the US health care system more productive and to bring costs down. The American Recovery and Reinvestment Act of 2009 included a \$14-27 billion provision - the Health Information Technology for Economic and Clinical Health (HITECH) - to reward health care providers for meaningful use of computing technology (Buntin, 2011). Signed into law in March 2010, the Affordable Care Act (ACA) is the most sweeping health care legislation passed by Congress since the adoption of Medicare in the 1960s (Huntoon, 2011). The precise impact of ACA will continue to be shaped by new rules and guidance developed by the federal agencies in support of the law. The Affordable Care Act (ACA) is designed to be a major step toward a system that is more cost effective, higher quality and more accessible. It is expected to add about 30 million new patients to the health care system (Buettgens, 2010).

Policy is a course or principle of action adopted or proposed by a government, party, business, or individual (Oxford Dictionary). Standards, guidelines, and theories become policies if and when they are consciously adopted to guide decisions or actions about evaluation and when the organization institutes consequences for encouraging or enforcing them (Trochim, 2009). A review of policy implementation literature finds the field split in two major schools - top-down and bottom-up (Matland, 1995). Top-down theorists see policy designers as the central actors and concentrate their attention on factors that can be manipulated at the central level. Three criticisms of the topdown approach are 1) not considering the significance of actions taken earlier in the policy-making process, 2) looking at implementation as a purely administrative process either ignoring the political aspects or trying to eliminate them, and 3) the emphasis on the statute framers as key actors. Bottoms-up theorists emphasize target groups and service deliverers, stating policy really is made at the local level (Matland, 1995). Two criticismx of the bottom-up model are 1) the idea that "policy control should be exercised by actors whose power derives from their accountability to voters through their elected representatives" and 2) is that this methodology overemphasizes the level of local autonomy (Matland, 1995).

Successful policy implementation generally requires a combination of pressure and support. Pressure alone may be sufficient when policy implementation requires no additional resources but cannot effect those changes in attitudes, beliefs, and routine practices that are needed to reform policies (McLaughlin, 1987). The balanced combination of the two is required to successfully implement policy changes.

The overarching conclusion from research on policy implementation is that it is very tough to implement new policies across layers of government and institutions (McLaughlin, 1987). Applying new policies has the potential to change many people's lives so critical evaluation of what is being implemented and how society views these changes will lead to a smoother transition. As difficult as it is to write a good policy, it is much harder to get the policy adopted widely (Gilbert, 1999). A way to measure adoption of change is the PAM which includes stages of perceived ease of use, perceived usefulness, and attitude towards use, age, and subject matter knowledge. PAM can be used as an aid in implementation by measuring the public's acceptance and can be used iteratively to find the best fit policy changes. There has not been an existing or newly designed model to integrate the acceptance analysis and evaluation of policies. To create this, the Technology Acceptance Model was extended to assess policy acceptance using PAM. This article introduces PAM using a quantitative survey-based approach. Research of the existing studies of Acceptance Models was evaluated and used to develop the extension. This information was then 
used to develop a quantitative survey which was given to a diverse population and will be investigated to find trends among various age groups and ethnicities.

\section{OVERVIEW OF RESEARCH AIMS AND HYPHOTHESES}

Policy is "a definite course or method of action selected from among alternatives to guide and determine present and future decisions" (Tableman, 2005). It represents a certain political, ethical, or programmatic viewpoint and governmental policy characterizes theoretical or experiential assumptions about what is required to resolve a particular issue or problem (Tableman, 2005). It has been shown that a balance between political pressure and support is essential for successful implementation (McLaughlin, 1987). Politicians often make decisions based on what they perceive as the "will of the majority" (Tableman, 2005). For a policy to become a law, there are many steps in the legislative process that require the initial idea to be approved by various areas of the government. Legislators often rely on information from grass roots organizations, their staff, and lobbyists (Tableman, 2005). Policy implementation has been an issue since the 1970s. With information coming in from such a wide variety of areas, it would be beneficial to uniformly collect data so that results can be clearly assessed. Ultimately, changes are not created or implemented by organizations, but rather by individuals and incentive and from professional and personal motivation (McLaughlin, 1987). New laws that go against typical routines, traditions, and resources are likely to be rejected. Policy effects are complex, often invisible, and unanticipated (McLaughlin, 1987).

\section{Architecture Of The Policy Acceptance Model}

Today, our society is continuously evolving and subjected to various cultural influences. Things that might be very logical and self-evident in one culture can be offensive or illogical in another. Culture influences our decisions and behavior and is a relevant factor when looking at what drives decisions. Innovators must investigate the end user's culture and understand the needs of the people before introducing new products or concepts. Cultural influence was included as a construct in this extended TAM for assessing acceptance of health care reform. In the context of this study, culture is defined as a person's ethnic background and age.

Ethnic background influences our choices and behavior and is a relevant factor when looking at what drives people's decisions. When manufactures create global products, they must investigate the consumer's background and understand the needs of the people in that ethnicity. A considerable amount of research exists to understand the adoption and diffusion of new ideas and little exists that examines ethnicity effects on the adoption and diffusion of new ideas (Straub, 1997).

\section{H1: Ethnicity will have an effect on PEOU and PU.}

There is evidence that age also has an important influence on acceptance of change. Studies suggest that there is a difference in information processing based on a person's age. Older adults have been shown to be among the last to adopt a product, service, or idea innovation (Gilly, 1985). Gaining a better understanding of age difference is important as it relates to user acceptance and usage of new systems and ideas. The world is shifting to a differing age structure due to the demographic transition with the majority of the world switching from high birth and death rates toward low birth and death rates (Denton, 2011). These diverse age structures are pushing policy makers to make trade-offs and make decisions considering generational equality which invest in the youth and provide support for the elderly (Denton, 2011). The different groups have contrasting policy concern in the areas of education, employment, migration, health care, and social security (Horrigmo, 2013).

H2: Age will have an effect on PEOU and PU.

H3: There is a greater positive association between people's ATT health care reform and BI versus the association between ATT and PU.

PAM is an instrument designed for the analysis and evaluation of user acceptance of governmental policies. Figure 3 summarizes the proposed research model structure for PAM which uses the base model of TAM and adds 
additional variables of age and ethnicity. The model suggests that age and ethnicity have an effect on attitude towards use and hence the acceptance of the policy.

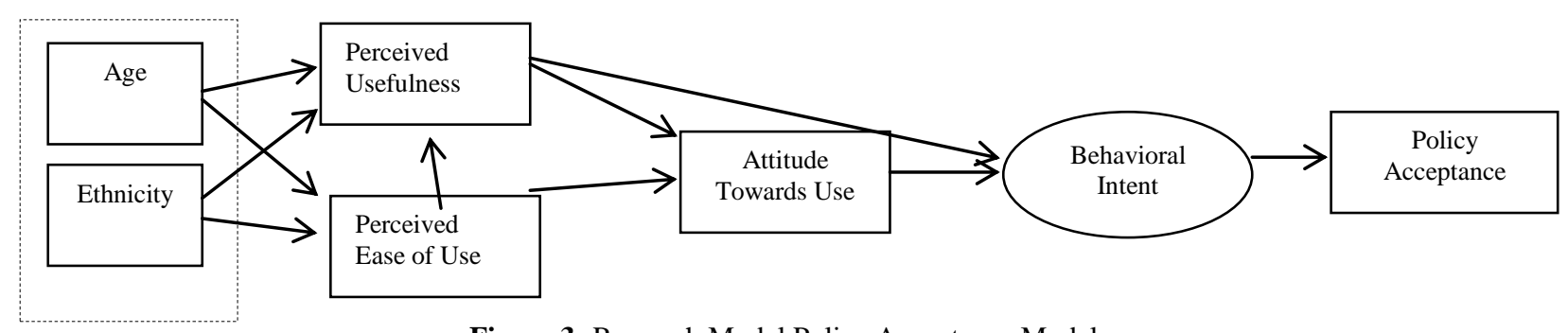

Figure 3: Research Model Policy Acceptance Model

\section{METHODOLOGY}

Research of the existing studies of Acceptance Models was evaluated and used to develop the Policy Acceptance Model which is an extension of the Technology Acceptance Model. A quantitative survey was developed (see Appendix A) and given to a diverse population and was used in investigating and finding trends among various ethnic backgrounds and ages. The population included individuals - age 18 and up - who volunteered to take the survey. Data were collected using a web-based survey instrument - E-Online Survey Creator. Participants were given a link to the website containing the survey that explains the purpose of the survey. The measurement instrument contains five parts. Demographic information was collected on respondents' gender, age, current employment status, education, ethnicity, and household income. The other parts covered the constructs of TAM, which include PEOU, PU, ATT, and BI. In addition, the survey contained six five-point Likert scale questions (strongly disagree, disagree, undecided, agree, and strongly agree). This study was reviewed and conducted with approval by the Institutional Review Board at The George Washington University.

The aim was to determine to what extent BI is associated with ATT, PU, and PEOU in the field of policy. The following steps were followed to achieve this. First, TAM constructs are measured where positive correlations between them are expected. Second, the study aimed to test whether, and to what extent, ATT mediate PU and PEOU effects BI using SEM. Third, using SEM, the study tested whether age influenced ATT and whether ethnicity affected BI.

\section{RESULTS}

Web-based surveys were conducted during June and August 2013 by inviting people across the United States to participate in the study. Participants were asked to self-assess their acceptance of the Affordable Care Act. Because the number of individuals who viewed the invitation to take the survey was unknown, the response rate could not be determined. SPSS was then used to analyze the results and answer the research questions that were proposed. A total of 112 questionnaires were collected with 40 incomplete surveys, leaving 72 to run the analysis (see Appendix B).

\section{Model Validity}

The research model (Figure 4) was tested using structural equation modeling software Analysis of Moment Structures 22 (AMOS 22). This is Structural Equation Modeling (SEM) software that uses Confirmatory Factor Analysis (CFA) to align the tested measures to the specific constructs and constraining the variances of each measure to the latent construct it should represent. In addition to assessing the degree to which each measure contributes to its latent construct, CFA also tests the separation between constructs by evaluating the fit in the overall model. SEM tests the relations among variables as they were assessed. Results of significance tests reflect not only the absolute magnitudes of path coefficients, such as the inter-correlations among the variables. Standardized path coefficients with absolute values less than 0.10 may indicate a small effect, while values around 0.30 have a medium effect and values greater than 0.50 have a large effect (Suhr). For example, the path from PEOU to BI seen below has a coefficient of 0.60 . What this means is that when PEOU increases by one standard 
deviation from its mean region, BI would be expected to increase by 0.60 its own standard deviations from its own mean, while holding all other relevant regional connections constant. The reverse is said for negative values.

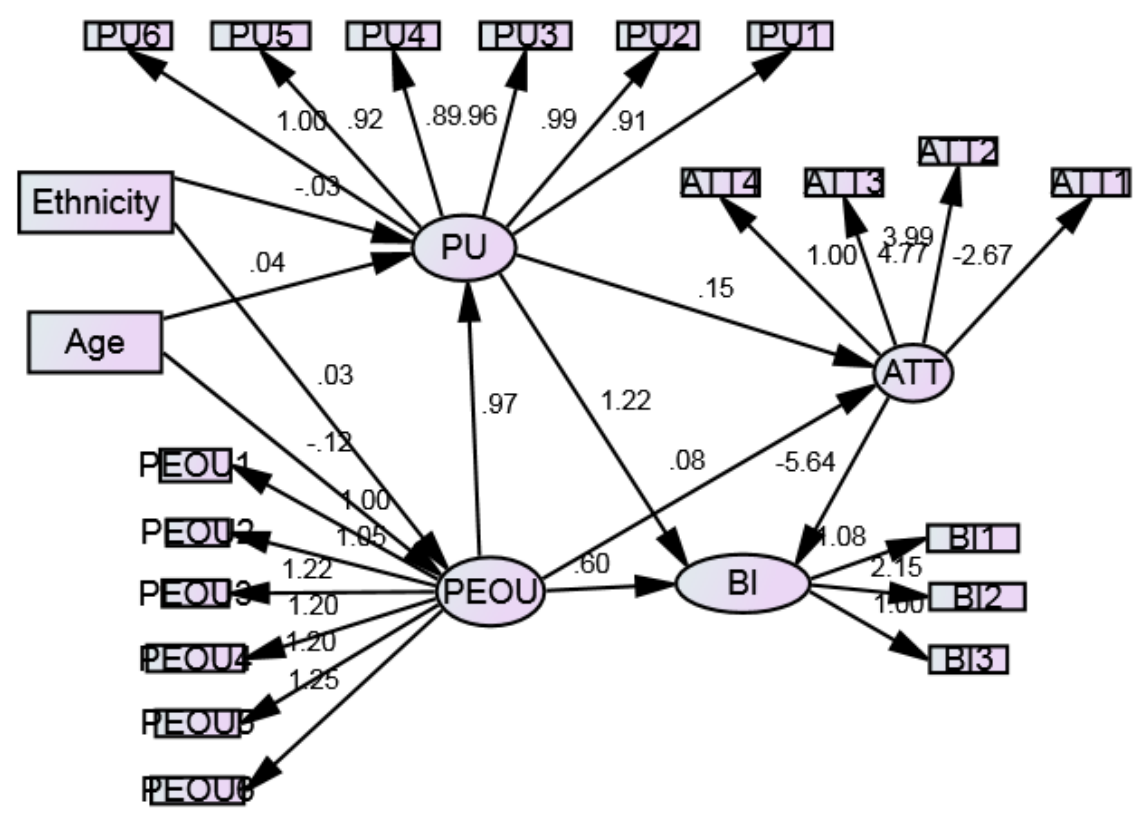

Figure 4: Structural Equation Model

The overall fit of the model was assessed using multiple model fit criteria, as suggested in the literature (Bollen, 1993; Hu, 1999). Eight goodness-of-fit indices were used, including chi-squared/degrees of freedom $(X 2 / d f)$, goodness of fit index (GFI), Incremental Fit Index (IFI), Tucker Lewis Index (TLI), Normed Fit Index (NFI), Comparative Fit Index (CFI), and Root Mean Square of Approximation (RMSEA). Table 2 summarizes the values observed in the study. The Chi-square analysis is significant, indicating a lack of fit. However, the value of Chi-square divided by degrees of freedom is approximately 1.69 , which is below the cutoff value suggested by Wheaton et al. (1977) and indicates a good fit (Davis, 1992). There is statistically significant support that the theoretical model fit rather well based on the obtained measurements in this table.

Table 2: Fit Of Model (AMOS)

\begin{tabular}{|l|l|c|}
\hline \multicolumn{1}{|c|}{ Fit Measures } & \multicolumn{1}{c|}{ Recommended Values } & Model Fit \\
\hline Chi-square & P $>0.05$ & $305 ; \mathrm{p}<0.001$ \\
\hline$X 2 / d f$ & A value close to 1 and not exceeding 5 indicates a good fit. & 1.690 \\
\hline GFI & GFI values close to 1 indicate a very good fit. & 0.725 \\
\hline IFI & IFI values close to 1 indicate a very good fit. & 0.90 \\
\hline TLI & TLI values close to 1 indicate a very good fit. & 0.888 \\
\hline NFI & A value close to 1 indicates a very good fit. & 0.792 \\
\hline CFI & A value close to 1 indicates a very good fit. & 0.902 \\
\hline RFI & RFI values close to 1 indicate a very good fit & 0.761 \\
\hline RMSEA & RMSEA below 0.1 indicates a good fit. & 0.097 \\
\hline
\end{tabular}

\section{Reliability}

The reliability coefficient used in this study is Cronbach's alpha (Table 3). This coefficient was chosen for several reasons, including: 1) alpha provides a measure of internal consistency of items forming a multi-item scale, 2 ) it is used to determine how much the items on a scale are measuring the same underlying dimension, 3 ) it is often used when you have multiple Likert questions in a survey/questionnaire that form a scale or subscale and you wish to determine if the scale is reliable. Higher values of Cronbach's alpha are better. What constitutes a good level of internal consistency differs on what source you refer to, although all recommended values are 0.7 or higher (Laerd Statistics). The reliabilities for each construct were within acceptable range for this research. 
Table 3: Reliability Statistics

\begin{tabular}{|l|c|c|}
\hline \multicolumn{1}{|c|}{ Construct } & Cronbach's Alpha & N Of Items \\
\hline PEOU & .890 & 6 \\
\hline PU & .973 & 6 \\
\hline ATT & .804 & 4 \\
\hline BI & .724 & 3 \\
\hline
\end{tabular}

\section{Correlation}

Construct validity of the model was evaluated by examining convergent and discriminant validity using both inter-item correlations. As summarized in Table 4, correlation is, on average, higher among items intended for the same construct than among those designed to measure different constructs.

Table 4: Analysis Of Inter-Measurement Correlation Matrix

\begin{tabular}{|c|c|c|c|c|c|c|c|c|c|c|c|c|c|c|c|c|c|c|c|}
\hline & PEOU1 & PEOU2 & PEOU3 & PEOU4 & PEOU5 & PEOU6 & PU1 & PU2 & PU3 & PU4 & PU5 & PU6 & Bi1 & $\mathrm{Bl} 2$ & $\mathrm{~B} 13$ & ATT1 & ATT2 & ATT3 & ATT4 \\
\hline PEOU1 & 1 & & & & & & & & & & & & & & & & & & \\
\hline PEOU2 & $.555^{*}$ & 1 & & & & & & & & & & & & & & & & & \\
\hline PEOU3 & $.660^{-*}$ & $.746^{-}$ & 1 & & & & & & & & & & & & & & & & \\
\hline PEOU4 & $.520^{*}$ & $.539^{--}$ & $.650^{-*}$ & 1 & & & & & & & & & & & & & & & \\
\hline PEOU5 & $.447^{-}$ & $.457^{--}$ & $.638^{--}$ & $.757^{-\cdots}$ & 1 & & & & & & & & & & & & & & \\
\hline PEOU6 & $410^{--}$ & $.387^{--}$ & $.584^{--}$ & $.628^{--}$ & $.620^{--}$ & 1 & & & & & & & & & & & & & \\
\hline PU1 & $609^{\circ}$ & $.495^{\circ}$ & $.572^{\prime \prime}$ & $.445^{\circ}$ & $.438^{\prime \prime}$ & $.437^{\prime \prime}$ & 1 & & & & & & & & & & & & \\
\hline PU2 & $.556^{*}$ & $.492^{\circ}$ & $.548^{\prime \prime}$ & $.403^{\circ}$ & $.436^{\circ}$ & $.476^{\circ}$ & $.829^{-*}$ & 1 & & & & & & & & & & & \\
\hline PU3 & $.559^{\prime \prime}$ & $.485^{\circ}$ & $.531^{\circ}$ & $.380^{\circ}$ & $.443^{\prime \prime}$ & $.492^{\prime \prime}$ & $.863^{*}$ & $.904^{-*}$ & 1 & & & & & & & & & & \\
\hline PU4 & $.531^{\prime \prime}$ & $.538^{\circ}$ & $.609^{\circ}$ & $.402^{\prime \prime}$ & $.513^{\prime \prime}$ & $.474^{\prime \prime}$ & $.7811^{-}$ & $.774^{-}$ & $.862^{-}$ & 1 & & & & & & & & & \\
\hline PU5 & .601 & $.419^{\prime \prime}$ & $.496^{\circ}$ & $.432^{\prime \prime}$ & $.444^{\prime \prime}$ & $.439^{\prime \prime}$ & $.876^{--}$ & $.877^{-*}$ & $.892^{*}$ & $.819^{--}$ & 1 & & & & & & & & \\
\hline PU6 & $.565^{\circ}$ & $.499^{\circ}$ & .551 & $.457^{\circ}$ & $.485^{\circ}$ & .501 & $.835^{--}$ & $.844^{-}$ & $.897^{-}$ & $.838^{-}$ & $.882^{--}$ & 1 & & & & & & & \\
\hline Bl1 & $.288^{\circ}$ & .172 & $.419^{\prime \prime}$ & .364 & $.427^{\prime \prime}$ & $.328^{\prime \prime}$ & $.468^{\circ}$ & $.403^{\prime \prime}$ & $.491^{\prime \prime}$ & $.488^{\prime \prime}$ & $.470^{\circ}$ & $.520^{\circ}$ & 1 & & & & & & \\
\hline $\mathrm{B} 12$ & $.638^{\circ}$ & $.471^{\prime \prime}$ & $.608^{\prime \prime}$ & $.533^{\circ}$ & $.487^{\prime \prime}$ & $.542^{\prime \prime}$ & $.778^{\prime \prime}$ & $.846^{\prime \prime}$ & $.843^{\prime \prime}$ & $.757^{\prime \prime}$ & $.826^{\prime \prime}$ & $.848^{\circ}$ & $.520^{\circ}$ & 1 & & & & & \\
\hline $\mathrm{Bl} 3$ & $.380^{\circ}$ & .216 & .301 & $.342^{\circ}$ & .321 & $.289^{\circ}$ & $.396^{\circ}$ & $.496^{\circ}$ & $.353^{\circ}$ & $.299^{\circ}$ & $.4288^{\circ}$ & .424 & $.419^{--}$ & $.464^{-}$ & 1 & & & & \\
\hline ATT1 & $-328^{\prime \prime}$ & -304 & $-340^{\circ}$ & -241 & -331 & $-335^{\prime \prime}$ & $-363^{\prime \prime}$ & -.522 & $-.506^{\prime \prime}$ & $.543^{\prime \prime}$ & $-469^{\prime \prime}$ & $-.426^{\prime \prime}$ & .005 & $-.485^{\prime \prime}$ & -109 & 1 & & & \\
\hline ATT2 & $.453^{\circ}$ & $.447^{\prime \prime}$ & $.480^{\circ}$ & $.438^{\circ}$ & $.479^{\circ}$ & $.525^{\prime \prime}$ & $.716^{\prime \prime}$ & $.693^{\prime \prime}$ & $.741^{\circ}$ & .704 & $.717^{*}$ & $.769^{\circ}$ & $.545^{\circ}$ & $.707^{*}$ & $.345^{\circ}$ & -.228 & 1 & & \\
\hline ATT3 & $.615^{\prime \prime}$ & .421 & $.548^{\prime \prime}$ & $.554^{\prime \prime}$ & $.520^{\circ}$ & $.551^{\prime \prime}$ & .724 & $.689^{\circ}$ & $.717^{\prime \prime}$ & $.689^{\circ}$ & .794 & $.805^{\circ}$ & $.4211^{11}$ & $.830^{\circ}$ & $.422^{\circ}$ & $-.391^{--}$ & $.683^{--}$ & 1 & \\
\hline ATT4 & .082 & $.295^{\circ}$ & $.256^{\circ}$ & $.326^{\circ}$ & $.376^{\circ}$ & .151 & .067 & .152 & .087 & .097 & .079 & .124 & .019 & .173 & .099 & -.125 & .077 & .089 & \\
\hline
\end{tabular}

\section{DISCUSSION AND CONCLUSIONS}

$\mathrm{H} 1$ is refuted with ethnicity not having an impact on PEOU and PU, with standardized path coefficients both being 0.03 and -0.03 . The study failed to refute H2. Age has an impact on PEOU with path coefficient of 0.12 and no impact on PU with path coefficient of 0.04. The data supported the individual causal paths postulated by TAM. PU was found to have a significant and strong influence on intention to accept the new policy with standardized path of 1.22. PU had a positive effect on attitude, but this was not of statistical significance with a value of 0.15 . Effects of attitude on intention were also shown to be significant with a value of -5.64 . PEOU has positive, but negligible, effect on ATT (0.08) and a positive significant effect on PU (0.97). The study also failed to refute H3. ATT was found to influence BI to a greater extent than PU with standardized path coefficients being 5.64 and 1.22, respectively. This suggests the importance of attitude of society's acceptance of new policies and its contribution in predicting implementation techniques.

Although this study has limitations, it is one of the first attempts to analyze the TAM model for policy acceptance. It (1) tests the TAM model with two additional variables and (2) verifies that existing TAM constructs can potentially be used to measure policy acceptance. 
The first limitation of this study is the population of respondents. The survey was distributed through online channels to collect results. Although it was posted and available to a diverse population, everyone may not have access to the internet and the sample was limited to those who are often online. The second limitation is the sample size. There was significance found in one of the hypothesized variables, but additional research is needed to test additional meaningful variables. Third, because a small number of respondents were over the age of 50, some may wonder whether the findings can be used to speak for the full population. Though different age groups may have different priorities, the construct did have a significant impact on intention to accept. Lastly, there may be other factors influencing people's acceptance of new policy that were not accounted for in the proposed model, such as location or occupation. Future research may explore these factors in an attempt to expand the scope and explanatory power of the proposed model.

\section{Implications For Research And Practice}

The current research represents an important contribution to theory by extending TAM to address the addition of causal antecedents to two of its belief constructs - perceived ease of use and perceived usefulness. The objective of the proposed study is to provide a quantitative output to use when introducing a new technique to measure the general public's policy acceptance. The research answers the question of whether age and ethnicity have an impact on policy acceptance or not. The research background begins with the evaluation of the Acceptance Models that have been developed throughout history. From this information, an extension of the TAM was developed which includes age and ethnicity as a factor in the diagram. The research model uses surveys from a diverse population of consumers on their acceptance of the new health care reform.

This study addresses several issues of potential relevance to policy creators. The findings of this study reveal that in order for society to buy into a new policy implementation, it is important to encourage and cultivate a positive attitude towards the change. Organizational implementers should survey user attitudes towards the changes being suggested in order to shape the creation of the policies.

This study observed that perceived ease of use and perceived usefulness were both significant factors on predicting acceptance. Positive perception of policy usefulness is very important, whereas ease of use is not equally as significant. This may help policy makers in the process of introducing new policies. Some possible ways to ease implementation include open forum discussions and early distribution of information which should focus on how a new policy will improve quality of life and reduce the complications of how current procedures are run.

The goal of this research was to construct and test the initial usage framework for Policy Acceptance Model. Future research is needed to look at additional variables that may have an effect on policy acceptance. Another area of expansion would be to perform the test on a larger population.

\section{AUTHOR INFORMATION}

Tamra Pierce is a Ph.D. candidate at The George Washington University pursuing a degree in Systems Engineering. She holds an MS in Systems Engineering from The George Washington University and a BS in Electrical Engineering and BS in Biomedical Engineering from the University of Miami. She currently works at CACI, Inc. as a systems design and test engineer. Prior to that, she worked at Lockheed Martin doing performance analysis and testing an air traffic control system for the FAA. Her research interests include system acceptance and implementation. Email: pierce16@gwu.edu. (contact author)

John E. Bischoff, D.Sc earned his doctorate in Engineering Management at The George Washington University. He also holds an MS in Telecommunications Management from Polytechnic University in New York, an MBA in Finance from Long Island University, and a BBA from Pace University. He currently serves as an Adjunct Professor in the EMSE graduate program at GWU and on the Board of Sea Wolf Ventures at the University of Alaska Anchorage. He formally served as the Vice President of Finance and Operations at America Online and as senior resource manager for the Computer Science group at IBM's Watson Research Laboratory. 
Robert A. Roncace received a D.Sc. degree in systems engineering from The George Washington University in 2006. From 1980 to 1994, he held a variety of positions as Mechanical Engineer and Systems Acquisition Program Manager in the U.S. Air Force. From 1996 through 2011, he was a Senior Engineer and Engineering Manager for The Boeing Company. He is currently employed as a Program Analyst with Avenge, Inc. Since 2006, he has taught courses as a part-time faculty Professorial Lecturer for the Engineering Management and Systems Engineering department at GWU. His research interests are in systems reliability and probabilistic risk analysis.

Christopher J. Willy received a D.Sc. degree in systems engineering from The George Washington University in 2008. From 1981 to 1999, he held a variety of positions as a Naval Flight Officer in the U.S. Navy. Since 1999, he has been employed as a senior systems engineer by J. F. Taylor, Inc., Lexington Park, Maryland. Since 2009, he has taught courses as a part-time faculty Professorial Lecturer for the Engineering Management and Systems Engineering department at GWU. His research interests are in stochastic processes and systems engineering.

\section{REFERENCES}

1. Aggelidis, V. \& Chatzoglou, P. (2009). Using a modified technology acceptance model in hospitals. International Journal of Medical Informatics, 78(2), 115-126.

2. Ajzen, I. (1991). The theory of planned behavior. Organizational Behavior and Human Decision Processes, 50, 179-211.

3. Amberg, M., Hirschmeier M., \& Wehrmann, J. (2004). The Compass Acceptance Model for the analysis and evaluation of mobile devices. Int. J. Mobile Communications, 3(2), 248-259.

4. Bollen, K. \& Long, J. Testing Structural Equation Modeling. California: Sage, 2009. Print.

5. Bricon-Souf, N. \& Newman, C. (2007). Context awareness in health care: A review. International Journal of Medical Informatics, 76, 2-12.

6. Buettgens, M., Garrett, B., \& Holahan, J. (2010). America Under the Affordable Care Act. Urban Institute.

7. Buntin, M., Burke, M., \& etc al. (2011). The Benefits of Health Information Technology: A Review of the Recent Literature Shows Predominantly Positive Results. Health Affairs, 30(3), 464-471.

8. Center for Public Health Policy. (2011). Update on Funding and Implementation of Public Health and Prevention Provision in the Patient Protection and Affordable Care Act (ACA). American Public Health Association.2.

9. Davis, F. (1985). A Technology Acceptance Model for Empirically Testing New End-User Information Systems: Theory and Results. (Doctoral dissertation). Retrieved from DSpace@MIT. (http://hdl.handle.net/1721.1/15192).

10. Davis, F. D. (1989). Perceived usefulness, perceived ease of use, and user acceptance of information technology. MIS Quarterly, 13(3), 319-340.

11. Davis, F. D., Bagozzi, R. P., \& Warshaw, P. R. (date). User acceptance of computer technology: a comparison of tow theoretical models. Management Science, 35(8), 982-1003.

12. Denton, H. (2011). How Changes in Age Structure can Impact Policy Making. SAIS Review, vol. XXXI, 2.

13. Fishbein, M. \& Ajzen, I. (1975). Belief, attitude, intention and behavior: An introduction to theory and research. Reading, MA: Addison-Wesley.

14. Ghazizadeh, M., Lee, J., \& Boyle, L. (2012). Extending the Technology Acceptance Model to assess automation. Springer Cogn Tech Work, 14:39-49.

15. Gilbert, T. \& Taylor, J. (1999). How to Evaluate and Implement Clinical Policies. Fam Pract Manag, 6(3): 28-33.

16. Harler, C. \& Stewers, R. (2012). How Affordable is the Affordable Care Act? SD\&I.

17. Holden, R. \& Karsh, B. (2010). The Technology Acceptance Model: Its Past and Its Future in Health Care. J Biomed Inform, 43(1), 159.

18. Horrigmo, A. (2013). Can Culture Explain Culture?: The Influence of Cultural Change on Municipal Spending on Cultural Policies. Sage Journal Urban Affairs Review, 49(3), 408-434.

19. http://www.healthit.gov downloaded January 15, 2014.

20. Hu, P., Chau, P., Sheng, O., \& Tam, K. (1999). Examining the Technology Acceptance Model Using Physician Acceptance of Telemedicine Technology. Journal of Management Information Systems, 16(2), 91. 
21. Huntoon, K., McCluney, C., Scannell, C., Wiley, E., \& Bruno R. (2011). Health care Reform and the Next Generation: United States Medical Student Attitudes toward the Patient Protection and Affordable Care Act. PLos ONE, 6(9), e23557.

22. Kocher, R. Health care Reform: Trends Driven by the Evolution of U.S. Health care Policy. Whitepaper.

23. Lim, W. and Ting, D. (2012). E-shopping: an Analysis of the Technology Acceptance Model. Modern Applied Science, 6(4), 49-62.

24. Mathieson, K. (1991). Predicting user intention: comparing the technology acceptance model with theory of planned behavior. Information Systems Research, 2(3), 173-191.

25. Matland, R. (1995). Synthesizing the Implementation Literature: The Ambiguity-Conflict of Policy Implementation. Journal of Public Administration Research and Theory, 5(2), 145-174.

26. McLaughlin, M. (1987). Learning from Experience: Lessons from Policy Implementation. Educational Evaluation and Policy Analysis, 9(2), 171-178.

27. Melas, C., Zampetakis, L., \& Dimopoulou, A. (2011). Modeling the acceptance of clinical information systems among hospital medical staff: An extended TAM model. Journal of Biomedical Informatics, 44, 553-564.

28. Meltzer, C. (2011). Summary of the Affordable Care Act. AJNR AM J Neuroradiol, 32, 1165-1166.

29. Morris, M., Venkatesh, V., \& Ackerman, P. (2005). Gender and Age Differences in Employee Decisions About New Technology: An Extension to the Theory of Planned Behavior. IEEE Transactions of Engineering Management, 52(1), 69-84.

30. Park, E. and Pobil, A. (2013). Technology Acceptance Model for the Use of Tablet PCs. Wireless Pers Commun, 73, 1561-1572.

31. Pavlou, P. (2003). Consumer Acceptance of Electronic Commerce: Integrating Trust and Risk with the Technology Acceptance Model. International Journal of Electronic Commerce, 7(3), 69-103.

32. $\quad$ "Policy". Oxford Dictionaries. Oxford University Press. http://www.oxforddictionaries.com/us/definition/american_english/policy (accessed January 20, 2014).

33. Read, W., Robertson, N., \& McQuilken, L. (2011). A novel romance: The Technology Acceptance Model with emotional attachment. Australasian Marketing Journal, 19, 223-229.

34. Rocker, C. (2010). Why Traditional Technology Acceptance Models Won't Work for Future Information Technologies? World Academy of Science, Engineering, and Technology, 65, 237-243.

35. Scott R. E. (2007). e-Records in health—preserving our future. International Journal of Medical Informatics; 76: 427-431.

36. Srite, M. and Karahanna, E. (2006). The Role of Espoused National Cultural Values in Technology Acceptance. MIS Quarterly, 30(3), 679-704.

37. Straub, D., Keil, M., \& Brenner, W. (1997). Testing the technology acceptance model across cultures: A three country study. Information \& Management, 33, 1-11.

38. Suhr, D. (date). The Basics of Structural Equation Modeling, University of North Colorado.

39. Szajna, B. (1996). Emperical evaluation of the revised technology acceptance model. Management Science, 42(1), 85-92.

40. Tableman, B. (2005). How Governmental Policy is Made. Best Practice Briefs, 34, http://outreach.msu.edu/bpbriefs/issues/brief34.pdf.

41. Taylor, S. \& Todd, P. (1995). Understanding information technology usage: a test of completing models. Information Systems Research, 6(2), 144-176.

42. Teo, T. (2010). Establishing gender structural invariance of technology acceptance model (TAM). The Asia-Pacific Education researcher, 19(2), 311-320.

43. Trochim, W. M. K. (2009). Evaluation policy and evaluation practice. Evaluation policy and evaluation practice. New Directions for Evaluation, 123, 13-32.

44. Vale, C. M. \& Leder, G. C. (2004). Students' views of computer-based mathematics in the middle years: Does gender make a difference? Education Studies in Mathematics, 56(3), 287-312.

45. Venkatesh, V., Morris, M. G., Davis, G. B., \& Davis, F. D. (2003). User acceptance of information technology: Toward a unified view. MIS Quarterly, 27(3), 425-478.

46. Venkatesh,V., Speier, C., \&Morris, M. G. (2002).User acceptance enablers in individual decision making about technology: Toward an integrated model. Decision Sciences, 33(2), 297-316.

47. Yu, J., Liu, C., \& Yao, J. (2003). Technology Acceptance model for wireless Internet. ABI/INFORM Global, 13(3), 206-222. 


\section{APPENDIX A}

Policy Acceptance Model Survey

\begin{tabular}{|c|c|c|c|}
\hline \multicolumn{4}{|c|}{ Survey Variables and Codes } \\
\hline \multicolumn{4}{|c|}{ Section 1: Background } \\
\hline $\mathbf{Q}$ & Variable & Value & Code \\
\hline \multirow{2}{*}{1} & Gender & Female & 1 \\
\hline & & Male & 2 \\
\hline \multirow{2}{*}{2} & Children & Yes & 1 \\
\hline & & No & 2 \\
\hline \multirow{4}{*}{3} & \multirow{4}{*}{ What is your age? } & 18-26 years & 1 \\
\hline & & $27-35$ years & 2 \\
\hline & & $36-49$ years & 3 \\
\hline & & Over 50 & 4 \\
\hline \multirow{4}{*}{4} & \multirow{4}{*}{$\begin{array}{l}\text { What is the highest Level of } \\
\text { Education you have obtained }\end{array}$} & High-school & 1 \\
\hline & & Bachelors & 2 \\
\hline & & Masters & 3 \\
\hline & & $\mathrm{JD} / \mathrm{MD} / \mathrm{PhD}$ & 4 \\
\hline \multirow{7}{*}{5} & \multirow{7}{*}{ Ethnicity (Choose One) } & White & 1 \\
\hline & & Hispanic/Latino & 2 \\
\hline & & Black/African American & 3 \\
\hline & & Hawaiian/Pacific Islander & 4 \\
\hline & & Asian & 5 \\
\hline & & American Indian & 6 \\
\hline & & Other & 7 \\
\hline \multirow{7}{*}{6} & \multirow{7}{*}{ Occupation (Choose One) } & Self Employed & 1 \\
\hline & & Homemaker & 2 \\
\hline & & Full time employee & 3 \\
\hline & & Part time employee & 4 \\
\hline & & Unemployed & 5 \\
\hline & & Full time student & 6 \\
\hline & & Business Owner & 7 \\
\hline \multirow{9}{*}{7} & \multirow{9}{*}{ Household Salary } & Under $\$ 20,000$ & 1 \\
\hline & & $\$ 20,000-\$ 39,999$ & 2 \\
\hline & & $\$ 40,000-\$ 59,999$ & 3 \\
\hline & & $\$ 60,000-\$ 79,000$ & 4 \\
\hline & & $\$ 80,000-\$ 99,999$ & 5 \\
\hline & & $\$ 100,000-\$ 119,999$ & 6 \\
\hline & & $\$ 120,000-\$ 149,999$ & 7 \\
\hline & & $\$ 150,000-\$ 179,999$ & 8 \\
\hline & & over $\$ 180,000$ & 9 \\
\hline
\end{tabular}




\begin{tabular}{|c|c|c|c|c|c|c|}
\hline \multicolumn{2}{|r|}{$\begin{array}{l}\text { Section II: Perceived Ease Of Use (PEOU) - The Degree } \\
\text { To Which A Person Believes That Using A Particular } \\
\text { System Would Be Free Of Effort (Davis, 1989) }\end{array}$} & \multirow[t]{2}{*}{$\begin{array}{l}\text { Strongly } \\
\text { Disagree } \\
\quad(1)\end{array}$} & \multirow[t]{2}{*}{$\begin{array}{l}\text { Disagree } \\
\quad(2)\end{array}$} & \multirow[t]{2}{*}{$\begin{array}{l}\text { Neither } \\
\text { Agree Nor } \\
\text { Disagree } \\
\text { (3) } \\
\end{array}$} & \multirow[t]{2}{*}{$\begin{array}{l}\text { Agree } \\
(4)\end{array}$} & \multirow[t]{2}{*}{$\begin{array}{l}\text { Strongly } \\
\text { Agree } \\
\text { (5) }\end{array}$} \\
\hline 8 & $\begin{array}{l}\text { Implementing the changes from health care reform will } \\
\text { be easy for me and/or my family. }\end{array}$ & & & & & \\
\hline 9 & $\begin{array}{l}\text { Learning the details of the health care reform was easy } \\
\text { for me and/or my family. }\end{array}$ & & & & & \\
\hline 10 & $\begin{array}{l}\text { The changes that have been implemented and are } \\
\text { coming are clear and understandable. }\end{array}$ & & & & & \\
\hline 11 & $\begin{array}{l}\text { I rarely become confused when I think about how the } \\
\text { health care changes will affect me and/or my family. }\end{array}$ & & & & & \\
\hline 12 & $\begin{array}{l}\text { It will be easy for me to become familiar with how the } \\
\text { health care changes will affect me and/or my family. }\end{array}$ & & & & & \\
\hline 13 & $\begin{array}{l}\text { I am rarely frustrated when hearing about the health } \\
\text { care reform. }\end{array}$ & & & & & \\
\hline \multicolumn{2}{|r|}{$\begin{array}{l}\text { Section III: Perceived Usefulness (PU) - The degree to } \\
\text { which a person believes that using a particular system } \\
\text { would enhance his or her job performance (Davis, 1989) }\end{array}$} & $\begin{array}{l}\text { Strongly } \\
\text { Disagree } \\
\quad(1)\end{array}$ & $\begin{array}{l}\text { Disagree } \\
\quad(2)\end{array}$ & $\begin{array}{l}\text { Neither } \\
\text { Agree Nor } \\
\text { Disagree } \\
\text { (3) }\end{array}$ & $\begin{array}{l}\text { Agree } \\
\text { (4) }\end{array}$ & $\begin{array}{l}\text { Strongly } \\
\text { Agree } \\
\text { (5) }\end{array}$ \\
\hline 14 & $\begin{array}{l}\text { The changes from the reform would enable me to } \\
\text { manage my health care more efficiently. }\end{array}$ & & & & & \\
\hline 15 & $\begin{array}{l}\text { The health care reform has improves my quality of } \\
\text { life. }\end{array}$ & & & & & \\
\hline 16 & $\begin{array}{l}\text { The health care reform makes me and or my family's } \\
\text { life easier. }\end{array}$ & & & & & \\
\hline 17 & $\begin{array}{l}\text { The health care reform gives me and/or my family } \\
\text { greater control over health care needs. }\end{array}$ & & & & & \\
\hline 18 & $\begin{array}{l}\text { The health care reform enhances me and/or my } \\
\text { family's life. }\end{array}$ & & & & & \\
\hline 19 & $\begin{array}{l}\text { The changes from the health care reform will benefit } \\
\text { me and/or my family. }\end{array}$ & & & & & \\
\hline \multicolumn{2}{|r|}{ Section IV: Attitude Towards Use (ATT) } & $\begin{array}{l}\text { Strongly } \\
\text { Disagree } \\
\quad(1)\end{array}$ & $\begin{array}{l}\text { Disagree } \\
\text { (2) }\end{array}$ & $\begin{array}{l}\text { Neither } \\
\text { Agree Nor } \\
\text { Disagree } \\
\text { (3) } \\
\end{array}$ & $\begin{array}{l}\text { Agree } \\
\text { (4) }\end{array}$ & $\begin{array}{l}\text { Strongly } \\
\text { Agree } \\
\text { (5) }\end{array}$ \\
\hline 20 & $\begin{array}{l}\text { I support repeal of recent health care reform } \\
\text { legislation. }\end{array}$ & & & & & \\
\hline 21 & I feel that the health care reform was needed. & & & & & \\
\hline 22 & Health care Reform will improve health care quality. & & & & & \\
\hline 23 & Health care Reform will expand access to health care. & & & & & \\
\hline \multicolumn{2}{|c|}{ Section IV: Behavioral Intention (BI) } & $\begin{array}{c}\text { Strongly } \\
\text { Disagree } \\
\text { (1) }\end{array}$ & $\begin{array}{l}\text { Disagree } \\
\text { (2) }\end{array}$ & $\begin{array}{c}\text { Neither } \\
\text { Agree Nor } \\
\text { Disagree } \\
(\mathbf{3}) \\
\end{array}$ & $\begin{array}{l}\text { Agree } \\
\text { (4) }\end{array}$ & $\begin{array}{c}\text { Strongly } \\
\text { Agree } \\
\text { (5) }\end{array}$ \\
\hline 24 & $\begin{array}{l}\text { I intend to adopt changes to my health care policy as } \\
\text { result of the reform as soon as possible. }\end{array}$ & & & & & \\
\hline 25 & $\begin{array}{l}\text { I look forward to the changes that are to come from } \\
\text { the health care reform. }\end{array}$ & & & & & \\
\hline 26 & $\begin{array}{l}\text { I intend to use as many of the benefits as possible } \\
\text { under the new coverage. }\end{array}$ & & & & & \\
\hline
\end{tabular}




\section{APPENDIX B}

Policy Acceptance Model Survey Results

\begin{tabular}{|c|c|}
\hline Gender & Percent \\
\hline Female & 66.7 \\
Male & 33.3 \\
Total & 100.0 \\
\hline
\end{tabular}

\begin{tabular}{|c|c|}
\hline Kids & Percent \\
\hline 1.0 & 38.9 \\
2.0 & 61.1 \\
Total & 100.0 \\
\hline
\end{tabular}

\begin{tabular}{|c|c|}
\hline Age & Percent \\
\hline 1.0 & 19.4 \\
2.0 & 34.7 \\
3.0 & 29.2 \\
4.0 & 16.7 \\
Total & 100.0 \\
\hline
\end{tabular}

\begin{tabular}{|c|c|}
\hline Education & Percent \\
\hline 1.0 & 20.8 \\
2.0 & 47.2 \\
3.0 & 23.6 \\
4.0 & 8.4 \\
Total & 100.0 \\
\hline
\end{tabular}

\begin{tabular}{|c|c|}
\hline Income & Percent \\
\hline 1.0 & 13.9 \\
2.0 & 16.7 \\
3.0 & 20.8 \\
4.0 & 16.7 \\
5.0 & 9.7 \\
6.0 & 5.6 \\
7.0 & 9.7 \\
8.0 & 2.8 \\
9.0 & 4.2 \\
Total & 100.0 \\
\hline
\end{tabular}

\begin{tabular}{|c|c|c|c|c|c|}
\hline & \multicolumn{5}{|c|}{ Percent (\%) } \\
\hline & 1.0 & 2.0 & 3.0 & 4.0 & 5.0 \\
\hline \multirow{6}{*}{$\begin{array}{l}\text { PEOU1 } \\
\text { PEOU2 } \\
\text { PEOU3 } \\
\text { PEOU4 } \\
\text { PEOU5 } \\
\text { PEOU6 }\end{array}$} & 9.7 & 12.5 & 29.2 & 37.5 & 11.1 \\
\hline & 16.7 & 30.6 & 19.4 & 29.2 & 4.2 \\
\hline & 15.3 & 33.3 & 23.6 & 23.6 & 4.2 \\
\hline & 13.9 & 34.7 & 18.1 & 27.8 & 5.6 \\
\hline & 12.5 & 30.6 & 19.4 & 27.8 & 9.7 \\
\hline & 25.0 & 25.0 & 15.3 & 22.2 & 12.5 \\
\hline
\end{tabular}

\begin{tabular}{|c|c|c|c|c|c|}
\hline & \multicolumn{5}{|c|}{ Percent (\%) } \\
\hline & 1.0 & 2.0 & 3.0 & 4.0 & 5.0 \\
\hline PU1 & 13.9 & 15.3 & 36.1 & 27.8 & 6.9 \\
\hline PU2 & 12.5 & $\begin{array}{ll}18.1 \\
\end{array}$ & 31.9 & 25.0 & 12.5 \\
\hline PU3 & 12.5 & 15.3 & 37.5 & 26.4 & 8.3 \\
\hline PU4 & 13.9 & 11.1 & 40.3 & 26.4 & 8.3 \\
\hline PU5 & 12.5 & 13.9 & 40.3 & 26.4 & 6.9 \\
\hline PE6 & 11.1 & 15.3 & 30.6 & 29.2 & 13.9 \\
\hline
\end{tabular}




\begin{tabular}{|c|c|c|c|c|c|}
\hline & \multicolumn{5}{|c|}{ Percent (\%) } \\
\hline & 1.0 & 2.0 & 3.0 & 4.0 & 5.0 \\
\hline \multirow{4}{*}{$\begin{array}{l}\text { ATT1 } \\
\text { ATT } 2 \\
\text { ATT } 3 \\
\text { ATT } 4\end{array}$} & 2.8 & 20.8 & 18.1 & 38.9 & 19.4 \\
\hline & 12.5 & 16.7 & 31.9 & 33.3 & 5.6 \\
\hline & 15.3 & 1.4 & 29.2 & 38.9 & 15.3 \\
\hline & 11.1 & 18.1 & 29.2 & 34.7 & 6.9 \\
\hline
\end{tabular}

\begin{tabular}{|c|c|c|c|c|c|}
\hline & \multicolumn{5}{|c|}{ Percent (\%) } \\
\cline { 2 - 7 } & $\mathbf{1 . 0}$ & $\mathbf{2 . 0}$ & $\mathbf{3 . 0}$ & $\mathbf{4 . 0}$ & $\mathbf{5 . 0}$ \\
\hline \multirow{2}{*}{ BI1 } & 8.3 & 22.2 & 29.2 & 34.7 & 5.6 \\
\cline { 2 - 7 } BI2 & 15.3 & 13.9 & 33.3 & 26.4 & 11.1 \\
\cline { 2 - 7 } BI3 & 6.9 & 5.6 & 23.6 & 38.9 & 25.0 \\
\hline
\end{tabular}

